\title{
The relationship between oxidative stress and autoimmunity in Hashimoto's thyroiditis
}

\author{
Ihsan Ates ${ }^{1}$, Fatma Meric Yilmaz ${ }^{2}$, Mustafa Altay ${ }^{1}$, Nisbet Yilmaz ${ }^{1}$, Dilek Berker ${ }^{3}$ \\ and Serdar Güler ${ }^{3}$ \\ Departments of ${ }^{1}$ Internal Medicine, ${ }^{2}$ Biochemistry and ${ }^{3}$ Endocrinology, Ankara Numune Training and \\ Research Hospital, Sinhiye, Ankara 06100, Turkey
}

Correspondence should be addressed

to I Ates

Email

dr.ihsanates@hotmail.com

\begin{abstract}
Objective: We have aimed to study the relation between Hashimoto's thyroiditis (HT) and thyroid autoantibodies and oxidative stress parameters in euthyroid, subclinical and overt hypothyroid stages.

Design and methods: A total of 124 patients were included in the study; 93 of whom were newly diagnosed with HT (31 patients in each of the euthyroid, subclinical hypothyroid and overt hypothyroid subgroups), aged over 18 and had not received any prior treatment and 31 of whom were healthy volunteers.

Results: Total oxidant status (TOS) and oxidative stress index (OSI) levels were higher, and total antioxidant status (TAS) and total thiol and arylesterase levels were lower in the overt hypothyroid group compared to other groups. TOS and OSI levels increased, and TAS levels decreased significantly in each phase from euthyroid, subclinical hypothyroid, to overt hypothyroid subgroups among HT patients. There was a negative correlation between TAS, log (paraoxonase1) and paraoxonase1/HDL and anti-thyroid peroxidase and a negative correlation between anti-thyroglobulin and total thiol. It was also determined that overt hypothroidism was an individual predictor that effects all of the oxidative stress parameters, but not total thiol, levels. Conclusion: Our results suggest that oxidative stress increases continuously during the development of subclinical hypothyroidism and overt hypothyroidism in patients with HT. To determine whether this is a cause or result, randomized, controlled trials that study the effect of antioxidant treatment on the development of overt hypothyroidism and its consequences, e.g., increase in total cholesterol levels, may be performed in euthyroid and/or subclinical hypothyroid patients with $\mathrm{HT}$.
\end{abstract}

European Journal of

Endocrinology

(2015) 173, 791-799

\section{Introduction}

Hashimoto's thyroiditis (HT) is a chronic autoimmune inflammatory disease of the thyroid gland. The $\mathrm{T}$ and $\mathrm{B}$ lymphocytes that are stimulated against thyroglobulin (TG) and thyroid peroxidase (TPO) cause thyroid destruction and inflammation in HT. The T and B lymphocytes may cause the excessive production of reactive oxygen species (ROS) through nicotinamide adenine dinucleotide phosphate (NADPH) oxidase (NOX) enzyme when they are stimulated $(1,2)$. In physiological conditions, ROS (hydrogen peroxide) are molecules that are necessary for the thyroid hormone synthesis (in iodine oxidation and binding to amino acids) within thyroid epithelial cells. However, there may be an excessive increase in the
(C) 2015 European Society of Endocrinology Printed in Great Britain hydrogen peroxide levels in the presence of some stimulants such as inflammation ( $\mathrm{T}$ and B lymphocyte activation), radiation, chemical materials, excessive iodine intake and drugs. In this milieu of excessively increased hydrogen peroxide, thyrocytes become apoptotic, necrotic and consequently destructed (3). In other words, free radicals, as soon as they are formed, damage the proteins, lipids, carbohydrates and DNA in the cells, leading to severe oxidative damage resulting in necrosis $(4,5)$.

Another situation that could lead to ROS increase in HT is the decrease in the antioxidant enzyme (superoxide dismutase, glutathion) synthesis, due to the decrease in thyroid hormone levels. Moreover, it is also known that

Published by Bioscientifica Ltd. 
hyperlipidemia that develops with the decrease in thyroid hormone levels also leads to an increase in $\operatorname{ROS}(6,7,8,9)$. There are many enzymatic or non-enzymatic molecules that reflect the oxidant and antioxidant status of the body. Total oxidant status (TOS) and total antioxidant status (TAS) reflects the general status of the oxidative levels in the body. The paraoxanase 1 (PON1) enzyme is a serum arylesterase enzyme that is closely bound with HDL, which protects LDL against oxidative damage. Thiols are compounds that comprise sulfhydryl $(\mathrm{SH})$ groups that are bound to carbon atoms. Total thiol (total SH) is an antioxidant that can react with free radicals to protect against tissue and cell damage that is caused by ROS (10).

Many studies have shown that $\mathrm{T}$ and $\mathrm{B}$ lymphocytes contribute to the pathogenesis of autoimmune diseases by the production of autoantibodies and ROS under environmental and genetic influence. For example, in systemic lupus erythematosus, which is an autoimmune disease, it has been proposed that oxidative stress may play a role in pathogenesis as well as increase in the course of the disease (11). Similarly, oxidative stress has also been demonstrated to be high in systemic sclerosis, another autoimmune disease (12). However, there are a number of studies in the literature examining the relation between oxidative stress and HT $(6,13,14,15)$. These studies had been performed on small patient populations, used only some of the oxidative stress parameters and yielded conflicting results. Thus, in this study we have aimed to investigate the relationship of a whole set of oxidative stress parameters with euthyroid, subclinical and overt hypothyroid stages of HT.

\section{Subjects and methods}

\section{Study population}

This study has been conducted at the departments of Internal Medicine and Endocrinology in the Ankara Numune Training and Research Hospital between September 2013 and September 2014.

A total of 124 subjects aged over 18 years were included in the study. Ninety-three patients newly diagnosed with HT, who had not received any treatment, formed the patient group, and 31 age-, BMI- and sexmatched healthy volunteers who were not suffering from any known diseases served as the control group. The patient group is divided further into three subgroups, each containing 31 patients: euthyroid, subclinical hypothyroidism and overt hypothyroidism. To provide homogeneity, patients in each subgroup are involved consecutively according to their laboratory data on a first come, first served basis.

Patients who had hypertension, diabetes mellitus, acute or chronic kidney disease, proteinuria at a nephrotic level, coronary artery disease, heart failure, peripheral artery disease, cerebrovascular disease, malignancy, liver diseases or disease related with rheumatism, or were taking antioxidant agents, lipid lowering drugs or vitamin supplements or smoked tobacco or consumed any amount of alcohol were not included in the study.

Hashimoto's thyroiditis was diagnosed when the antiTG and/or anti-TPO was positive in the serum together with the presence of parenchymal heterogeneity on thyroid ultrasonography (USG). Patients who had HT were further classified as euthyroid (free thyroxine $\left(\mathrm{fT}_{4}\right.$ ) and thyroid stimulating hormones (TSH) within normal ranges), subclinical hypothyroidism (normal $\mathrm{fT}_{4}$ and elevated TSH levels) and overt hypothyroidism (increased $\mathrm{TSH}$ with low $\mathrm{fT}_{4}$ levels).

All of the subjects in the control group had normal serum TSH, $\mathrm{fT}_{4}$, anti-TG and anti-TPO levels and normal thyroid imaging (homogenous parenchyma without nodules) on USG.

The BMI was calculated by dividing the body weight $(\mathrm{kg})$ with the square of height in meters $\left(\mathrm{BMI}=\mathrm{kg} / \mathrm{m}^{2}\right)$.

The study was conducted in accordance with the Declaration of Helsinki 2013 Brasil version and was approved by the Local Ethics Research Committee. All subjects provided written informed consent prior to participation in the study.

\section{Biochemical parameters}

Venous blood samples were obtained from all subjects in both groups after an overnight fast between 0800 and 0900 and immediately centrifuged for $10 \mathrm{~min}$ at $1500 \mathrm{~g}$; serum samples were stored at $-80^{\circ} \mathrm{C}$ until assay. Then, all oxidative stress parameters were measured in the same serum sample at once.

The TSH, $\mathrm{fT}_{4}$, anti-TPO and anti-TG were measured with a Cobas e 601 (Catolog No: 11731459122, 03051986190, 1173129722, 06368697190, Roche Diagnostics, Mannhaim, Germany) autoanalyzer using the electrochemyluminescence immunoassay method. The total cholesterol and triglyceride were measured with a Hitachi Modular P800 (Roche Diagnostics Corp.) autoanalyzer using the enzymatic colorimetric method, and HDL was measured using the cholesterol homogenous enzymatic colorimetric method. LDL cholesterol was calculated with the Friedewald formula (16). 


\section{Assays for oxidants and antioxidants}

Serum TOS level was measured with the colorimetric method by means of a commercial kit (Rel Assay Diagnostics, Gaziantep, Turkey, REF. No: RL0024, LOT No: JE 14048Og) with \%CV, ten and linearity, 0-33.5 $\mu \mathrm{mol} / 1$.

Serum TAS levels were measured with the colorimetric method using a commercial kit (Rel Assay Diagnostics, REF. No: RL0017, LOT No: JE 14042A) with \%CV, ten and linearity, 0-2.75 $\mathrm{mmol} / \mathrm{l}$.

Serum total SH levels were measured with the colorimetric method using a commercial kit (Rel Assay Diagnostics, REF. No: RL0178, LOT No: AL 13011TL).

Serum PON1 levels were measured with the colorimetric method using a commercial kit (Rel Assay Diagnostics, REF. No: RL0031, LOT No: JE14028P) with $\% \mathrm{CV}$, five, and linearity, 0-750 U/1.

Serum arylesterase levels were measured with the colorimetric method using a commercial kit (Rel Assay Diagnostics, REF. No: RL0055, LOT No: JR13017AR).

Oxidative stress index is calculated by dividing TOS ( $\mu$ mol $\mathrm{H}_{2} \mathrm{O}_{2}$ equivalent/l) into TAS (mmol Trolox equivalent/l). There is no standard value or a range for an OSI level; it is only used to make comparisons between groups (17).

\section{Thyroid ultrasonography evaluation}

Thyroid USG was carried out with a Logic 7 (General Electric Med, Inc., Milwaukee, USA) USG device having a $7.5 \mathrm{MHz}$ probe by the same radiologist who was completely blind for the diagnosis of the patient.

\section{Statistical analysis}

Statistical evaluation has been carried out using the Statistical Package for Social Sciences for Windows, version 20.0 (IBM SPSS, Inc.) Software. The normal distribution of data was evaluated with the KolmogorovSmirnov test. Numerical variables that do not show normal distribution have been converted into normal distribution using logarithmic conversion. Numerical variables were shown as mean \pm s.D. Categorical variables were defined as numbers and percentages. The ANOVA test was used to compare the risk factors of the control, euthyroid, subclinical and overt hypothyroidism patients, and the Bonferroni correction $T$-test was used in all binary comparisons. $\chi^{2}$ and Fisher's absolute $\chi^{2}$-test were used to compare categorical data. The risk factors that affected the levels of oxidative stress parameters were determined by linear regression analysis. A $P$ value $<0.05$ was accepted to be statistically significant in all comparisons.

\section{Results}

The demographic, characteristic and laboratory findings of all groups are summarized in Table 1 . The population of the study consisted of 124 patients with equal numbers of euthyroid $(n=31)$, subclinical hypothyroidism $(n=31)$

Table 1 Demographic, characteristics and the distribution of laboratory findings to the control and patient groups. Categorical variables were shown in numbers and percentage; numerical variables were shown as mean \pm s.D.

\begin{tabular}{|c|c|c|c|c|c|}
\hline Variables & Control $(n=31)$ & Euthyroid $(n=31)$ & $\begin{array}{c}\text { Subclinical } \\
\text { hypothyroidism } \\
(n=31)\end{array}$ & $\begin{array}{c}\text { Overt } \\
\text { hypothyroidism } \\
(n=31)\end{array}$ & $\boldsymbol{P}$ \\
\hline Gender, male $n(\%)$ & $7(22.6)$ & $7(22.6)$ & $7(22.6)$ & $7(22.6)$ & 0.999 \\
\hline Age (years) & $41.3 \pm 8.8$ & $41.5 \pm 8.6$ & $41.3 \pm 10.8$ & $41.4 \pm 13.9$ & 0.999 \\
\hline BMI $\left(\mathrm{kg} / \mathrm{m}^{2}\right)$ & $28.1 \pm 4.1$ & $28.2 \pm 4.6$ & $28.3 \pm 4.7$ & $28.4 \pm 5.9$ & 0.997 \\
\hline TSH $(\mu \mathrm{IU} / \mathrm{ml})$ & $1.9 \pm 0.7^{a, b}$ & $2.3 \pm 0.9^{a, b}$ & $6.3 \pm 2.3^{b, c, d}$ & $30.5 \pm 12.1^{a, c, d}$ & $<0.001 *$ \\
\hline $\mathrm{fT}_{4}(\mathrm{ng} / \mathrm{dl})$ & $1.0 \pm 0.1^{\mathrm{b}}$ & $1.1 \pm 0.1^{b}$ & $1.1 \pm 0.1^{b}$ & $0.7 \pm 0.1^{a, c, d}$ & $0.014 *$ \\
\hline Anti-TG (IU/ml) & $15.4 \pm 6.1^{a, b, d}$ & $389.4 \pm 134.7^{a, b, c}$ & $477.7 \pm 147.6^{b, c, d}$ & $690.3 \pm 124.8^{a, c, d}$ & $0.005^{*}$ \\
\hline Anti-TPO (IU/ml) & $9.02 \pm 4.25^{a, b, d}$ & $153.46 \pm 76.4^{a, b, c}$ & $241.57 \pm 66.1^{c, d}$ & $262.4 \pm 58.7^{c, d}$ & $0.001 *$ \\
\hline $\mathrm{TC}(\mathrm{mg} / \mathrm{dl})$ & $188.7 \pm 30.9^{b}$ & $191.3 \pm 37.9^{b}$ & $193.2 \pm 40.7^{b}$ & $215.4 \pm 41.1^{a, c, d}$ & $0.024 *$ \\
\hline TG (mg/dl) & $113.6 \pm 61.9$ & $117.1 \pm 88.7$ & $127.7 \pm 74.5$ & $129.97 \pm 74.0$ & 0.794 \\
\hline LDL (mg/dl) & $111.1 \pm 25.1$ & $111.6 \pm 32.5$ & $115.9 \pm 34.9$ & $109.1 \pm 41.8$ & 0.878 \\
\hline HDL (mg/dl) & $50.3 \pm 10.7^{b, d}$ & $57.2 \pm 14.8^{a, c}$ & $50.7 \pm 12.1^{b, d}$ & $57.7 \pm 13.5^{a, c}$ & $0.033 *$ \\
\hline Non-HDL (mg/dl) & $133.8 \pm 29.9$ & $134.7 \pm 39.9$ & $141.7 \pm 39.8$ & $133.8 \pm 49.1$ & 0.839 \\
\hline
\end{tabular}

TC, total cholesterol; TG, thyroglobulin; TSH: thyroid stimulating hormone; $\mathrm{fT}_{4}$, free thyroxin; anti TG, anti thyroglobulin; anti TPO, anti thyroid peroxidase; TC, total cholesterol; TG, triglyceride. ${ }^{*} P<0.05$ statistically significant (ANOVA test).

a Different from the subclinical group (Bonferroni test $P<0.05$ ).

${ }^{b}$ Different from the hypothyroid group (Bonferroni test $P<0.05$ ).

'Different from the control group (Bonferroni test $P<0.05$ ).

dDifferent from the euthyroid group (Bonferroni test $P<0.05$ ). 
and overt hypothyroidism $(n=31)$ with HT and the healthy control ( $n=31)$ group. All four groups were similar with regard to age, BMI and sex. Total cholesterol levels were higher in overt hypothyroid patients than in the other two patient subgroups (subclinical hypothyroid and euthyroid) and the controls (215.4 \pm 41.1 vs $193.2 \pm 40.7$ vs $191.3 \pm 37.9$ vs $188.7 \pm 30.9, P=0.024$, respectively). Euthyroid, subclinical hypothyroid and control groups had similar total cholesterol levels. Triglyceride, LDL and non-HDL levels did not show any differences among the groups. The HDL levels were similar between euthyroid and overt hypothyroid patients but were higher in these groups than the subclinical hypothyroidism and control groups $(57.2 \pm 14.8$ vs $57.7 \pm 13.5$ vs $50.7 \pm 12.1$ vs $50.3 \pm$ $10.7, P=0.033$, respectively). The levels of oxidative stress parameters are presented in Table 2.

The mean TAS levels were lower in overt hypothyroid patients in comparison to other groups, whereas it was similar between the control, euthyroid and subclinical hypothyroid groups $(1.5 \pm 0.2$ vs $1.7 \pm 0.1$ vs $1.7 \pm 0.1$ vs $1.7 \pm 0.1, P<0.001$, respectively).

The mean OSI and mean TOS levels were higher in the overt hypothyroidism group than in the other groups $(4.3 \pm 2.3$ vs $2.9 \pm 0.8$ vs $3.0 \pm 1.1$ vs $2.4 \pm 0.7, P<0.001$; $6.5 \pm 1.9$ vs $5.0 \pm 1.3$ vs $5.1 \pm 1.9$ vs $4.1 \pm 1.1, P=0.006$, respectively). Although mean OSI and mean TOS levels were similar between euthyroid and subclinical hypothyroid groups, they were higher in these two groups than the controls.

The mean total SH levels were higher in the euthyroid group compared to all other groups. Although mean total SH levels were similar in the control and subclinical hypothyroid groups, they were higher than the overt hypothyroid group $(487.1 \pm 45.1$ vs $461.1 \pm 41.6$ vs $466.6 \pm 51.3$ vs $442.8 \pm 63.9, P=0.015$, respectively).

The mean arylesterase level was lower in the overt hypothyroid group than the other groups and was higher in the control group than the other groups. A significant difference was not found in the arylesterase level between the euthyroid and subclinical hypothyroid groups $(1180.4 \pm 284.9$ vs $1374.3 \pm 180.1$ vs $1233.1 \pm 248.5$ vs $1230.3 \pm 231.8, P=0.018$, respectively).

The mean PON1/HDL and logarithmic (log)(PON1) levels were higher in the control group than all three patient groups but were similar between the HT patient subgroups. There were negative correlations between antiTPO and TAS, $\log (\mathrm{PON} 1)$ and PON1/HDL and a negative correlation between anti-TG and total SH in all three of the HT subgroups but not in the control group (Table 3).

In the regression model, the presence of hypothyroidism was found to be the independent predictor that affects the levels of TAS, TOS, OSI, log (PON1), arylesterase and PON1/HDL ratios. The independent predictors that affected the total SH level were anti-TG and age. Independent predictors that affect the TAS level were found to be the presence of hypothyroidism, TSH level and age (Table 4).

\section{Discussion}

In our study, the oxidative stress level was higher in all stages of HT when compared to the control group. There was a negative correlation between thyroid autoantibodies and total antioxidant homeostasis. In addition, the presence of hypothyroidism, a condition in which thyroid hormone deficiency, autoimmunity and inflammation

Table 2 The level of all oxidative stress parameters according to groups.

\begin{tabular}{l} 
Variables \\
\hline TAS (mmol Trolox equivalent/l) \\
TOS (Imol $\mathrm{H}_{2} \mathrm{O}_{2}$ equivalent/l) \\
OSi (arbitrary unit) \\
Total SH (mmol/l) \\
Arylesterase (U/I) \\
Log (PON1) (U/I) \\
PON1/HDL
\end{tabular}

\begin{tabular}{c} 
\\
Control $(n=31)$ \\
\hline $1.7 \pm 0.1^{a}$ \\
$4.1 \pm 1.1^{a, c, d}$ \\
$2.4 \pm 0.7^{a, c, d}$ \\
$461.1 \pm 41.6^{a, c}$ \\
$1374.3 \pm 180.1^{a, c, d}$ \\
$2.3 \pm 0.2^{a, c, d}$ \\
$4.2 \pm 1.1^{a, c, d}$
\end{tabular}

\begin{tabular}{c}
\hline \\
Euthyroid $(n=31)$ \\
\hline $1.7 \pm 0.2^{a}$ \\
$5.0 \pm 1.3^{a, b}$ \\
$2.9 \pm 0.8^{a, b}$ \\
$487.1 \pm 45.1^{a, b, d}$ \\
$1233.1 \pm 248.5^{a, b}$ \\
$2.1 \pm 0.2^{b}$ \\
$2.5 \pm 0.8^{b}$
\end{tabular}

\begin{tabular}{c}
$\begin{array}{c}\text { Subclinical } \\
\text { hypothyroidism } \\
(n=31)\end{array}$ \\
\hline $1.7 \pm 0.1^{\mathrm{a}}$ \\
$5.1 \pm 1.9^{\mathrm{a}, \mathrm{b}}$ \\
$3.0 \pm 1.1^{\mathrm{a}, \mathrm{b}}$ \\
$466.6 \pm 51.3^{\mathrm{a}, \mathrm{c}}$ \\
$1230.3 \pm 231.8^{\mathrm{a}, \mathrm{b}}$ \\
$2.1 \pm 0.3^{\mathrm{b}}$ \\
$2.8 \pm 0.7^{\mathrm{b}}$ \\
\hline
\end{tabular}

\begin{tabular}{|c|c|}
\hline $\begin{array}{c}\text { Overt } \\
\text { hypothyroidism } \\
(n=31)\end{array}$ & $\boldsymbol{P}$ \\
\hline $1.5 \pm 0.2^{b, c, d}$ & $<0.001 *$ \\
\hline $6.5 \pm 1.9^{b, c, d}$ & 0.006 * \\
\hline $4.3 \pm 2.3^{b, c, d}$ & $<0.001 *$ \\
\hline $442.8 \pm 63.9^{b, c, d}$ & $0.015 *$ \\
\hline $1180.4 \pm 284.9^{b, c, d}$ & $0.018 *$ \\
\hline $2.1 \pm 0.3^{b}$ & $0.005 *$ \\
\hline $2.7 \pm 0.9^{b}$ & 0.003 * \\
\hline
\end{tabular}

TAS, total antioxidant status; TOS, total oxidant status; OSI, oxidative stress index; total SH, total thiol; Log (PON1), logarithmic paraoxonase 1; PON1, Paraoxonase 1. Numerical variables were shown as average \pm s.D. ${ }^{*} P<0.05$ statistically significant (ANOVA test).

${ }^{a}$ Different from the hypothyroid group (Bonferroni test $P<0.05$ ).

${ }^{b}$ Different from the control group (Bonferroni test $P<0.05$ ).

'Different from the euthyroid group (Bonferroni test $P<0.05$ ).

${ }^{\mathrm{d} D i f f e r e n t}$ from the subclinical group (Bonferroni test $P<0.05$ ).

www.eje-online.org 


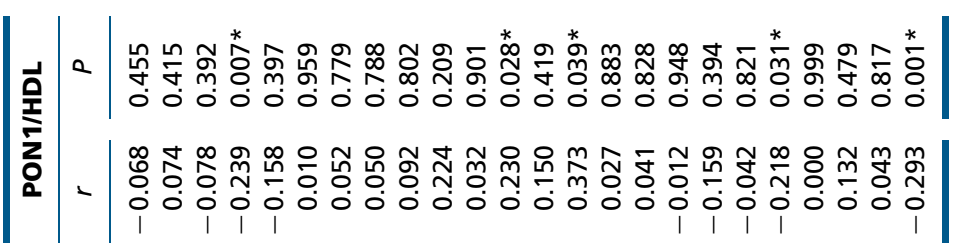

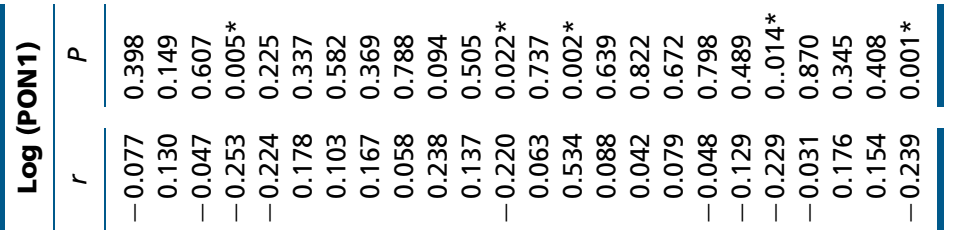

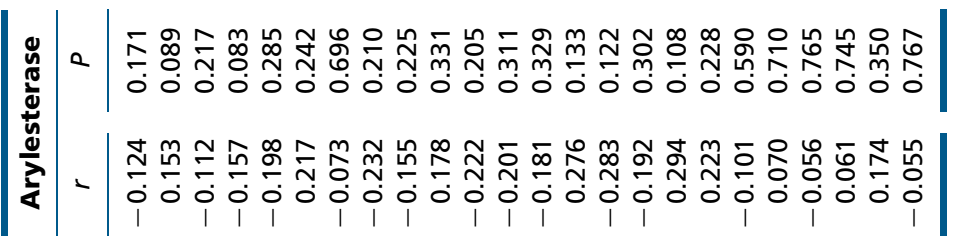

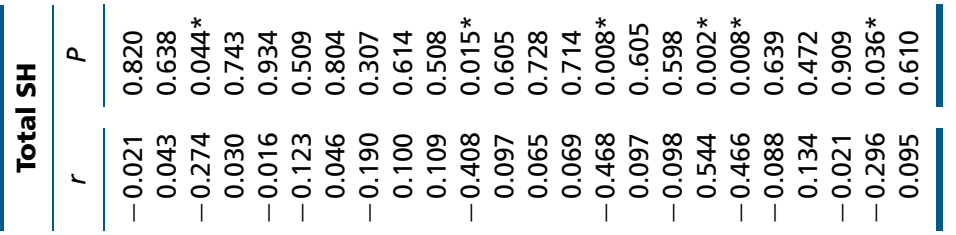

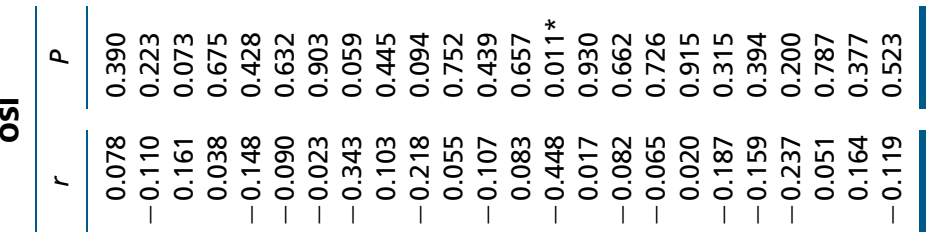

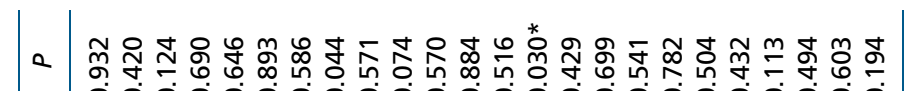

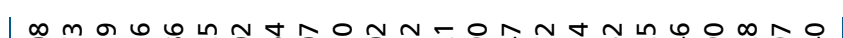

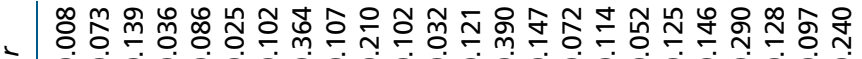

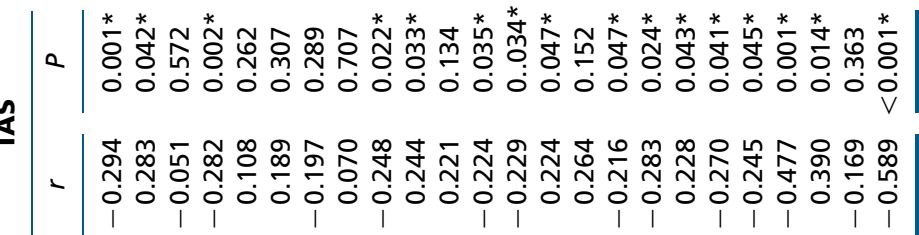


Table 4 Predictors of oxidative stress levels. The risk factors that are related to the linear regression model during correlation analysis were included.

\begin{tabular}{|c|c|c|c|c|}
\hline \multirow[b]{2}{*}{ Variables } & \multirow[b]{2}{*}{$\beta \pm$ S.E.M } & \multicolumn{2}{|c|}{$\% 95 \mathrm{Cl}$} & \multirow[b]{2}{*}{$\boldsymbol{P}$} \\
\hline & & Lower & Upper & \\
\hline \multicolumn{5}{|l|}{ TAS } \\
\hline Hypothyroidism & $-2.100 \pm 0.490$ & -3.070 & -1.120 & $<0.001 *$ \\
\hline $\mathrm{TSH}$ & $-0.300 \pm 0.100$ & -0.500 & -0.100 & $0.006 *$ \\
\hline Age & $0.700 \pm 0.200$ & 0.300 & 1.200 & 0.001 * \\
\hline \multicolumn{5}{|l|}{$R^{2}=0.408, P<0.001$} \\
\hline TOS & & & & \\
\hline \multicolumn{5}{|l|}{$R^{2}=0.344, P=0.006$} \\
\hline \multicolumn{5}{|l|}{ OSI } \\
\hline \multicolumn{5}{|l|}{$R^{2}=0.305, P=0.012$} \\
\hline \multicolumn{5}{|l|}{ Total SH } \\
\hline Anti-TG & $-0.550 \pm 0.170$ & -0.900 & -0.190 & $0.026^{*}$ \\
\hline Age & $-1.598 \pm 0.481$ & -2.561 & -0.635 & $0.002 *$ \\
\hline \multicolumn{5}{|l|}{$R^{2}=0.294, P=0.002$} \\
\hline \multicolumn{5}{|l|}{ Arylesterase } \\
\hline \multicolumn{5}{|l|}{$R^{2}=0.231, P=0.004$} \\
\hline \multicolumn{5}{|l|}{$\log ($ PON1) } \\
\hline Hypothyroidism & $-1.630 \pm 0.600$ & -2.830 & -0.420 & $0.009 *$ \\
\hline $\begin{array}{l}R^{2}=0.298, P=0.002 \\
P O N 1 / \mathrm{HDL}\end{array}$ & & & & \\
\hline $\begin{array}{l}\text { Hypothyroidism } \\
R^{2}=0.209, P=0.009\end{array}$ & $-1.430 \pm 0.528$ & -2.486 & -0.375 & $0.009 *$ \\
\hline
\end{tabular}

${ }^{*} P<0.05$ is considered significant for statistical analyses. $\beta$, regression coefficient; TAS, total antioxidant status, TSH, thyroid stimulating hormone; TOS, total oxidant status; OSI, oxidative stress index; total SH, total thiol; anti Tg, anti thyroglobulin; Log (PON1), logarithmic paraoxonase 1; PON1, paraoxonase 1.

is more dominant, was found to be an independent predictor affecting the levels of oxidative stress parameters (TAS, TOS, OSI, $\log$ (PON1), arylesterase and PON1/HDL). To the best of our knowledge, this study is the first to investigate the relationship between different stages of HT and a whole set of oxidative stress parameters (TAS, TOS, OSI, $\log (\mathrm{PON} 1)$, arylesterase, total SH and PON1/HDL).

Oxidative stress occurs as a result of overproduction of free oxygen radicals and deficiency of antioxidant defense systems (18). The ROS are primarily responsible for tissue damage due to oxidative stress. There are many internal and external sources of ROS. However, it is thought that the major sources are the respiratory redox chain of mitochondria and free radicals inside cells (19).

There are a number of studies in the literature examining the relation between oxidative stress and HT $(6,13,14)$. Baser et al. (20) reported lower TAS and higher TOS levels in euthyroid HT patients compared to healthy controls. In the study by Wang et al. (21) performed to determine the level of oxidative stress in patients with thyroid cancer, Graves' disease, HT and a control group, the TAS level was found to be lower, while TOS and OSI were found to be higher in the hypothyroid group than in the healthy control group. Supporting the results of the aforementioned studies, our results also showed higher TOS and OSI levels in the HT group than the healthy controls. The TAS level, on the other hand, was lower in overt hypothyroidism when compared to other groups. This condition may be related to an increased oxidative stress level due to inflammation, which plays a role in the pathogenesis of HT. The role of inflammation on oxidative stress can be explained in two ways. First, inflammation directly increases the level of hydrogen peroxide in thyroid epithelial cells, and second, it activates NOX enzyme in $\mathrm{T}$ and $\mathrm{B}$ lymphocytes, which increases ROS production $(22,23)$. In fact, the Th1 cytokines (predominant in HT) are known to decrease DUOX and thus $\mathrm{H}_{2} \mathrm{O}_{2}$ production but to increase NOX2 (without affecting NOX4) (24). Another reason for the determination of a low TAS level in the hypothyroidism group compared to other groups may be a decreased thyroid hormone level, because thyroid hormones are known to affect synthesis and bioactivity of antioxidant enzymes $(25,26)$. In a study conducted by Reddy etal., (27) the antioxidant defense in subclinical and overt hypothyroidism was examined and the decrease of antioxidant defense in overt 
hypothyroidism was thought to be a result from both the decrease in antioxidant enzyme synthesis and the low antioxidant enzyme activity. In this case, by externally providing antioxidant molecules, the possibility of preventing the development progression of overt hypothyroidism in HT should be considered and prospective studies should be planned in this direction. Likewise, positive effects of antioxidant treatment in Graves' patients on Graves' progression and complications have been shown before (28).

In this study we have found higher oxidant status parameters and lower antioxidant parameters in patients with hypothyroidism, in whom thyroid autoantibodies were also significantly higher, than the other groups, as well as negative correlations between thyroid autoantibodies and TAS. Concordant with our data, Nanda et al. had reported higher oxidative stress levels in the anti-TPOpositive hypothyroid patients compared to the anti-TPOnegative hypothyroid patient. These may be due to an increased oxidative stress level in autoimmunity-related inflammation and an increased oxidative stress level during inflammation.

In the study by Baskol et al. (29) performed in HT patients with hypothyroidism, the PON level was found to be lower in patients with hypothyroidism than in the healthy control group. Similarly, Cebeci et al. (30) revealed in their study that PON and arylesterase levels were lower in patients with subclinical hypothyroidism when compared to the healthy control group.

Similar to the above studies, we have also found lower arylesterase and $\log (\mathrm{PON} 1)$ levels in patients with subclinical and overt hypothyroidism than in the healthy controls. Besides, arylesterase was lower in patients with overt hypothyroidism when compared to patients with subclinical hypothyroidism. Low levels of arylesterase and $\log (\mathrm{PON} 1)$ may be related to either increased lipid peroxidation because it has been shown that oxidized lipids inhibit the activity of PON or increased ROS levels in hypothyroidism that may inactivate PON and thus lower its concentration (31).

In our study, total $\mathrm{SH}$ was found to be significantly lower in the overt hypothyroid group when compared to the healthy control group. Low total SH may be due to excessive production of ROS during inflammation and consumption of non-enzymatic antioxidants of the body including glutathione (GSH). In other words, free radicals that are increased in the body during various pathologic conditions cause oxidation of $\mathrm{SH}$ groups of sulphurcontaining amino acids of proteins leading to reduced total body - SH levels $(32,33)$. We did not find any study in the literature evaluating the relationship between total SH and HT. Rostami et al. (15) had reported lower GSH levels, which constitutes the major intracellular SH, in HT than in the healthy controls, and Pasupathi et al. (34) had found lower GSH levels in patients with hypothyroidism than in the healthy control group.

In our study we have also found a lower PON1/HDL ratio in the HT group than in the healthy controls. We could not find any study in the literature evaluating the relationship between thyroid diseases and PON1/HDL, another parameter reflecting antioxidant status. Yıldiz et al. (35) carried out a study on patients with newly diagnosed hypertension and demonstrated that the PON/HDL ratio was lower in non-dipper hypertensive patients when compared to dipper hypertensive patients (35).

In our study, we have found a negative correlation between anti-TPO and TAS, $\log (\mathrm{PON} 1)$ and PON1/HDL and a negative correlation between anti-TG and total SH. Thyroid autoantibodies being correlated negatively with antioxidant molecules may suggest that HT may be related to oxidative stress. When studies investigating the relationship between oxidative stress parameters and thyroid autoantibodies were evaluated, a negative correlation was present between the TAS level and anti-TG and anti-TPO, while a positive correlation was present between TOS and anti-TG in the study by Baser et al. (20). Nanda et al. found a positive correlation of the oxidant molecules malondialdehyde and protein carbonyl with anti-TPO (36). In the study by Rostami et al., (15) GSH was negatively correlated with anti-TPO.

The fact that hypothyroidism was found as a risk factor affecting the levels of oxidative stress parameters by linear regression analysis proves that oxidative stress is related to both thyroid hormone deficiency as well as inflammation and autoimmunity. The major limitations of this study include the lack of an inflammatory marker directly showing the relationship between oxidative stress and inflammation and the cross-sectional nature of the study.

In conclusion, our data show that oxidant status is increased and antioxidant status is decreased in HT. In addition, among different stages of HT, oxidant status was highest and antioxidant status was lowest in the overt hypothyroid group. To determine whether this is a cause or result, randomized, controlled trials that study the effect of antioxidant treatment on the development of overt hypothyroidism and its consequences, e.g., increase in total cholesterol levels, may be performed in euthyroid and/or subclinical hypothyroid patients with HT. 


\section{Declaration of interest}

The authors declare that there is no conflict of interest that could be perceived as prejudicing the impartiality of the research reported.

\section{Funding}

This study did not receive any specific grant from any funding agency in the public, commercial or not-for-profit sector.

\section{Author contribution statement}

I Ates, F M Yilmaz and S Güler are responsible for the conception, design and manuscript writing. All authors contributed to data collection and data interpretation and approved the manuscript submitted to the European Journal of Endocrinology.

\section{References}

1 Jackson SH, Devadas S, Kwon J, Pinto LA \& Williams MS. T cells express a phagocyte-type NADPH oxidase that is activated after T cell receptor stimulation. Nature Immunology 20045 818-827. (doi:10.1038/ni1096)

2 Williams MS \& Kwon J. T cell receptor stimulation, reactive oxygen species, and cell signaling. Free Radical Biology \& Medicine 200437 1144-1151. (doi:10.1016/j.freeradbiomed.2004.05.029)

3 Poncin S, Gerard AC, Boucquey M, Senou M, Calderon PB, Knoops B, Lengele B, Many MC \& Colin IM. Oxidative stress in the thyroid gland: from harmlessness to hazard depending on the iodine content. Endocrinology 2008149 424-433. (doi:10.1210/en.2007-0951)

4 Beckman KB \& Ames BN. Endogenous oxidative damage of mtDNA. Mutation Research 1999424 51-58. (doi:10.1016/S0027-5107(99) 00007-X)

5 Evans MD \& Cooke MS. Factors contributing to the outcome of oxidative damage to nucleic acids. BioEssays 200426 533-542. (doi:10.1002/bies.20027)

6 Santi A, Duarte MM, Moresco RN, Menezes C, Bagatini MD, Schetinger MR \& Loro VL. Association between thyroid hormones, lipids and oxidative stress biomarkers in overt hypothyroidism. Clinical Chemistry and Laboratory Medicine 201048 1635-1639. (doi:10.1515/CCLM.2010.309)

7 Nanda N, Bobby Z, Hamide A, Koner BC \& Sridhar MG. Association between oxidative stress and coronary lipid risk factors in hypothyroid women is independent of body mass index. Metabolism $2007 \mathbf{5 6}$ 1350-1355. (doi:10.1016/j.metabol.2007.05.015)

8 Carmeli E, Bachar A, Barchad S, Morad M \& Merrick J. Antioxidant status in the serum of persons with intellectual disability and hypothyroidism: a pilot study. Research in Developmental Disabilities 200829 431-438. (doi:10.1016/j.ridd.2007.08.001)

9 Nanda N, Bobby Z \& Hamide A. Oxidative stress and protein glycation in primary hypothyroidism. Male/female difference. Clinical and Experimental Medicine 20088 101-108. (doi:10.1007/s10238-0080164-0)

10 McCord JM. Human disease, free radicals, and the oxidant/antioxidant balance. Clinical Biochemistry 199326 351-357. (doi:10.1016/ 0009-9120(93)90111-I)

11 Perl A. Oxidative stress in the pathology and treatment of systemic lupus erythematosus. Nature Reviews. Rheumatology 20139 674-686. (doi:10.1038/nrrheum.2013.147)

12 Grygiel-Gorniak B \& Puszczewicz M. Oxidative damage and antioxidative therapy in systemic sclerosis. Mediators of Inflammation 2014 2014 389582. (doi:10.1155/2014/389582)
13 Torun AN, Kulaksizoglu S, Kulaksizoglu M, Pamuk BO, Isbilen E \& Tutuncu NB. Serum total antioxidant status and lipid peroxidation marker malondialdehyde levels in overt and subclinical hypothyroidism. Clinical Endocrinology 2009 70 469-474. (doi:10.1111/j.1365-2265. 2008.03348.x)

14 Yilmaz S, Ozan S, Benzer F \& Canatan H. Oxidative damage and antioxidant enzyme activities in experimental hypothyroidism. Cell Biochemistry and Function 200321 325-330. (doi:10.1002/cbf.1031)

15 Rostami R, Aghasi MR, Mohammadi A \& Nourooz-Zadeh J. Enhanced oxidative stress in Hashimoto's thyroiditis: inter-relationships to biomarkers of thyroid function. Clinical Biochemistry 201346 308-312. (doi:10.1016/j.clinbiochem.2012.11.021)

16 Friedewald WT, Levy RI \& Fredrickson DS. Estimation of the concentration of low-density lipoprotein cholesterol in plasma, without use of the preparative ultracentrifuge. Clinical Chemistry 1972 18 499-502.

17 Ulas T, Buyukhatipoglu H, Kirhan I, Dal MS, Ulas S, Demir ME, Eren MA, Ucar M, Hazar A, Kurkcuoglu IC et al. Evaluation of oxidative stress parameters and metabolic activities of nurses working day and night shifts. Revista da Escola de Enfermagem da U S P 201347 471-476.

18 Ates I, Ozkayar N, Topcuoglu C \& Dede F. Relationship between oxidative stress parameters and asymptomatic organ damage in hypertensive patients without diabetes mellitus. Scandinavian Cardiovascular Journal 2015 1-23. (doi:10.3109/14017431.2015. 1060355)

19 Villanueva I, Alva-Sanchez C \& Pacheco-Rosado J. The role of thyroid hormones as inductors of oxidative stress and neurodegeneration. Oxidative Medicine and Cellular Longevity 20132013218145. (doi:10.1155/2013/218145)

20 Baser H, Can U, Baser S, Yerlikaya FH, Aslan U \& Hidayetoglu BT. Assesment of oxidative status and its association with thyroid autoantibodies in patients with euthyroid autoimmune thyroiditis. Endocrine 201548 916-923. (doi:10.1007/s12020-014-0399-3)

21 Wang D, Feng JF, Zeng P, Yang YH, Luo J \& Yang YW. Total oxidant/antioxidant status in sera of patients with thyroid cancers. Endocrine-Related Cancer 201118 773-782. (doi:10.1530/ERC-11-0230)

22 Bedard K \& Krause KH. The NOX family of ROS-generating NADPH oxidases: physiology and pathophysiology. Physiological Reviews 2007 87 245-313. (doi:10.1152/physrev.00044.2005)

23 Segal BH, Grimm MJ, Khan AN, Han W \& Blackwell TS. Regulation of innate immunity by NADPH oxidase. Free Radical Biology \& Medicine 201253 72-80. (doi:10.1016/j.freeradbiomed.2012.04.022)

24 Colin IM, Poncin S, Leveque P, Gallez B \& Gerard AC. Differential regulation of the production of reactive oxygen species in Th1 cytokine-treated thyroid cells. Thyroid 201424 441-452. (doi:10.1089/ thy.2013.0142)

25 Pereira B, Rosa LF, Safi DA, Bechara EJ \& Curi R. Control of superoxide dismutase, catalase and glutathione peroxidase activities in rat lymphoid organs by thyroid hormones. Journal of Endocrinology 1994 140 73-77. (doi:10.1677/joe.0.1400073)

26 Fernandez V \& Videla LA. Hepatic glutathione biosynthetic capacity in hyperthyroid rats. Toxicology Letters 199689 85-89. (doi:10.1016/ S0378-4274(96)03791-5)

27 Reddy VS, Gouroju S, Suchitra MM, Suresh V, Sachan A, Srinivasa Rao PV \& Bitla AR. Antioxidant defense in overt and subclinical hypothyroidism. Hormone and Metabolic Research 201345 754-758. (doi:10.1055/s-0033-1348262)

28 Guerra LN, Moiguer S, Karner M, de Molina MC, Sreider CM \& Burdman JA. Antioxidants in the treatment of Graves disease. IUBMB Life 200151 105-109. (doi:10.1080/15216540152122102)

29 Baskol G, Atmaca H, Tanriverdi F, Baskol M, Kocer D \& Bayram F. Oxidative stress and enzymatic antioxidant status in patients with hypothyroidism before and after treatment. Experimental and Clinical Endocrinology \& Diabetes 2007115 522-526. (doi:10.1055/ s-2007-981457) 
30 Cebeci E, Oner FA, Usta M, Yurdakul S \& Erguney M. Evaluation of oxidative stress, the activities of paraoxonase and arylesterase in patients with subclinic hypothyroidism. Acta Biomaterialia 201182 214-222. (doi:10.231/JIM.0b013e31823581dd)

31 Aviram M, Rosenblat M, Billecke S, Erogul J, Sorenson R, Bisgaier CL, Newton RS \& La Du B. Human serum paraoxonase (PON 1) is inactivated by oxidized low density lipoprotein and preserved by antioxidants. Free Radical Biology \& Medicine 199926 892-904. (doi:10.1016/S0891-5849(98)00272-X)

32 Requejo R, Hurd TR, Costa NJ \& Murphy MP. Cysteine residues exposed on protein surfaces are the dominant intramitochondrial thiol and may protect against oxidative damage. FEBS Journal 2010277 1465-1480. (doi:10.1111/j.1742-4658.2010.07576.x)
33 Thomas JA, Poland B \& Honzatko R. Protein sulfhydryls and their role in the antioxidant function of protein S-thiolation. Archives of Biochemistry and Biophysics 1995319 1-9. (doi:10.1006/abbi.1995. 1261)

34 Pasupathi PL. Free radical activity and antioxidant defense mechanisms in patients with hypothyroidism. Thyroid Science 20083 1-6.

35 Yildiz A, Gur M, Demirbag R, Yilmaz R, Akyol S, Aslan M \& Erel O. Paraoxonase and arylesterase activities in untreated dipper and nondipper hypertensive patients. Clinical Biochemistry 200841 779-784. (doi:10.1016/j.clinbiochem.2008.02.010)

36 NivediteNanda ZBvAH. Oxidative stress in anti thyroperoxidase antibody positive hypothyroid patients. Asian Journal of Biochemistry 20127 54-58. (doi:10.3923/ajb.2012.54.58)

Received 23 June 2015

Revised version received 9 August 2015

Accepted 4 September 2015 